\title{
General Aspects and Historical Background
}

Marco Bandini

\section{Summary}

The scope of catalytic enantioselective Friedel-Crafts alkylations is expanding rapidly and since the seminal papers appeared in the mid 1980s, numerous examples featuring enantioselectivities higher than $90 \%$ have been published. At present, nearly all the organic compounds displaying electrophilic character have been reacted with aromatic systems in FC-type alkylation reactions. However, the typology of reagents becomes slightly narrower if we limit the survey to approaches that employ chiral catalysts capable of traducing stereochemistry in the final products. Activated as well as unactivated carbon-carbon double bonds and $\mathrm{C}=\mathrm{X}$ frameworks characterize the most used classes of electrophilic agents, that are generally combined with privileged chiral organometallic and organic catalysts. It is also worth mentioning the actual distribution of enantioselective FC processes based on the type of aromatic system employed. Interestingly, highly reactive electron-rich arenes (pyrrole and indole) still constitute almost $80 \%$ of catalytic enantioselective FC-processes, while asymmetric transformations of benzene-like compounds are quite undeveloped.

\section{1}

\section{Introduction}

The Friedel-Crafts (FC) alkylation of aromatic compounds is one of the cornerstones of organic chemistry. Since it was first reported (three consecutive notes appeared in Comptes Rendus de l'Académie des Sciences in 1877) [1] by Charles Friedel and James Mason Crafts, countless versions of this process have been reported. In this context, it is worth mentioning that "... one third of worldwide organic chemical production involves aromatic compounds..." [2] with the consequent synthetic interest in their chemical manipulation.

The reaction introduced by the European (CF, Strasbourg, France, 1832-1889) and the youngest American (JMC, Boston, MA, USA, 1839-1917) researchers [3], has always been the subject of lively scientific debate, and one of the most controversial aspects is the definition of the process. 
It can be seen from the more than one hundred papers rapidly published by Crafts and Friedel on the topic that there is not only one but numerous organic transformations that can be listed under the name of FC-alkylation. In particular, Olah and Dear concluded in their outstanding treatise on FC-reactions (1963) that "... today we consider Friedel-Crafts type reactions to be any isomerization, elimination, cracking, polymerization, or addition reactions taking place under the catalytic effect of Lewis acid type ... or protic acids" [3].

Nowadays, this view has probably altered, and although the original experiments addressed the breaking of a $\mathrm{C}-\mathrm{H}$ bond in aliphatic compounds, the actual definition of FC processes is restricted to the specific functionalization of aromatic systems, namely alkylation and acylation reactions.

Most importantly, FC processes are probably the oldest organic transformations requiring metal halides (known as Lewis acids (LAs), e.g., aluminum trichloride, zinc chloride, boron trifluoride, ferric chloride etc.), as chemical promoters (catalysts).

Over more than 130 years, the original scope of the reaction has been significantly enlarged. Chemical aspects (e.g., reactivity, selectivity) combined with environmental concerns associated with the production/use of poorly manageable catalysts and the disposal of hazardous wastes have prompted many chemists to re-address their research toward the discovery of greener and economically viable alternatives. At present, a FC alkylation reaction constitutes an essential synthetic step in a number of commercial processes in the bulk chemical industry. From a restricted and merely indicative survey of the SciFinder Scholar (ACS), CARPLUS, and MEDLINE databases for the term "Friedel-Crafts alkylation" (1928-2007) emerged a striking increase in the use of FC-processes in organic synthesis (Figure 1.1).

These numbers would be even more impressive if FC-acylation reactions were also included.

Due to the intrinsic industrial interest in this transformation, most of these reports still focus exclusively on the use of recoverable solid Lewis acid promoters, however, since the late 1990s, an expanding volume of effort facing challenging issues such as catalysis and stereocontrol in alkylations of aromatic compounds has begun. Here, before moving to a more specific description of the actual landmarks regarding chiral organic and organometallic catalysis for the construction of enantiomerically

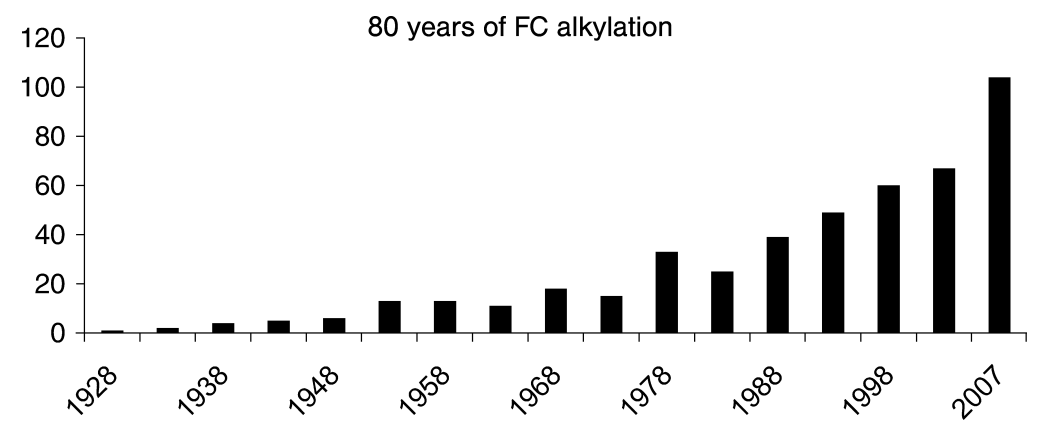

Figure 1.1 Number of published papers on FC-alkylation reactions (1928-2007). 
enriched benzylic stereocenters, a brief overview of general aspects of the Friedel-Crafts reaction is provided in the following sections.

\section{2}

\section{General Aspects and Historical Background}

Friedel-Crafts alkylation processes involve the replacement of a $\mathrm{C}-\mathrm{H}$ atom of an aromatic ring by an alkyl group " $\mathrm{R}^{+}$" in the presence of a Lewis or Brønsted acid catalyst (Scheme 1.1).

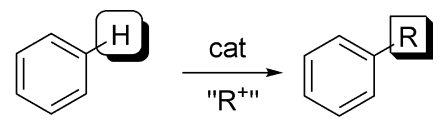

cat: Lewis or Brønsted acid

Scheme 1.1 Pictorial representation of the Friedel-Crafts alkylation.

Textbooks of basic organic chemistry usually mention exclusively the use of reactive alkyl halides in combination with aromatics. However, as partially outlined in the following chapters, activated and unactivated alkenes, alkynes, paraffins, alcohols, ethers, carbonyl compounds and so on, can also be effectively employed as alkylation agents.

A range of molecular Lewis acids with order of catalytic power: $\mathrm{AlBr}_{3}>\mathrm{AlCl}_{3}>$ $\mathrm{GaCl}_{3}>\mathrm{FeCl}_{3}>\mathrm{SbCl}_{5} \mathrm{TiCl}_{4}, \mathrm{ZnCl}_{2}>\mathrm{SnCl}_{4}>\mathrm{BCl}_{3}, \mathrm{BF}_{3}$ [4], modified solid LAs and Brønsted-Lowry acids ( $\left.\mathrm{HF}, \mathrm{H}_{3} \mathrm{PO}_{4}, \mathrm{H}_{2} \mathrm{SO}_{4}\right)$ have proved efficient in accelerating this process. The right choice of the additive to be employed is often a matter of trial and error, because a narrow correlation between type of alkylation agent and reactivity of aromatic compounds frequently occurs.

The reactivity of aromatics is another key aspect that soon emerged from the seminal studies of FC alkylation reactions. As known, by considering benzene as an electron-neutral arene, substitution with electron-donating groups (EDGs) usually increases the nucleophilic character of the aromatic compound and causes substitution to occur predominantly at the ortho and para positions. In contrast, electron-withdrawing groups (EWGs) deactivate the arene toward alkylation processes with a concomitant meta-oriented regiochemistry.

There are of course many exceptions to these trends. For instance, the substitution of aromatic compounds with strongly coordinating electron-releasing substituents such as, hydroxy, alkoxy, amino, and so on, quenches the catalytic performance of the catalyst by deactivating interactions and, additionally, the original electron-donating group is transformed into a deactivating substituent (Scheme 1.2).

Despite the great volume of effort devoted to gaining insight into the role of the acid catalyst in the mechanism of the reactions, an unequivocal and clear answer is still lacking. It should be mentioned that, although organometallic intermediates like " $\mathrm{C}_{6} \mathrm{H}_{5} \cdot \mathrm{Al}_{2} \mathrm{Cl}_{5}$ " were proposed by the authors in the original papers, here Friedel and Crafts finally stated "Nous n'avons donc encore aucune preuve décisive à apporter en 


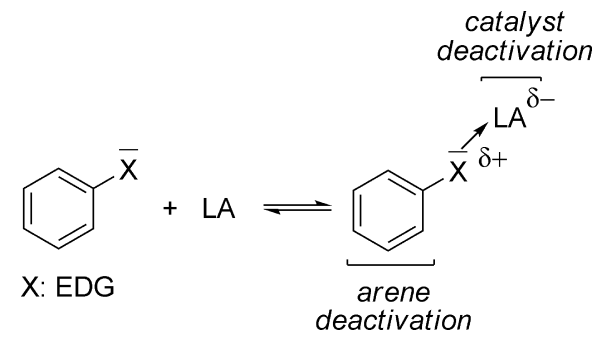

Scheme 1.2 Trapping of Lewis acids by coordinating heteroatomic substituents.

faveur de l'hypothèse que nous faisons sur le mécanisme de la réaction. .." (we do not have any decisive proof to support the hypothesis of the reaction mechanism).

In this context, the requirement of acid additives for optimal reaction outcomes suggests that an interaction of the promoting agent (A) with a donor species (D), present in solution, is operating in the process. Among all the possible combinations, the catalyst-alkylating agent (1) and the catalyst-substrate interactions (2) are considered essential for the process. On the contrary, the complexation of the catalyst by the product/s (3) will preclude irremediably its availability for the reaction course.

By considering the alkylation of arenes with alkyl halides $(\mathrm{R}-\mathrm{X})$ as the model reaction, it is largely accepted that the Lewis/Brønsted acid initially interacts with the reagent, through an $n$-donor interaction (Scheme 1.3a) [5]. This complexation weakens the $\mathrm{R}-\mathrm{X}$ bond with the formation of highly reactive carbonium ion $\left[\mathrm{R}^{+}\right]$ feasible during the reaction course. The existence of such an interaction has been proved experimentally through numerous chemical and physical investigations [6], however, in no case was it possible to shed light on the existence of alkyl cation complexes as reaction intermediates.

A breakthrough in the field was achieved by the Nobel Laureate in Chemistry, George A. Olah (1994), who proved the existence of "long-lived" long alkyl chain cations by employing "superacids" (HF. $\left.\mathrm{SbF}_{5}\right)$ in combination with alkyl fluorides [7].

However, the possibility that the acid species could interact directly with the $\pi$-rich aromatic counterpart, via either $\pi$-complexes (all the six electrons of the arenes interact with the LA, Scheme 1.3b) or $\sigma$-complexes (formation of arenonium species, Scheme $1.3 \mathrm{c}$ ) cannot be ruled out $[8,9]$. Here, the intermediate originated from a $\pi$-donor interaction between arene and catalyst is generally characterized by low

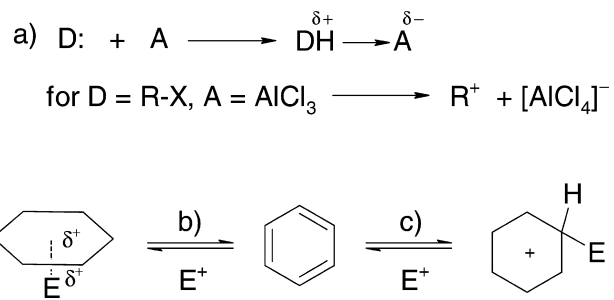

Scheme 1.3 Types of intermediate complexes in FC alkylations:

(a) carbonium ion, (b) $\pi$-complexes, (c) $\sigma$-complexes. 
stability with a marginal role in the FC mechanistic cycle. On the contrary, with $\sigma$-donor-like contacts, a new covalent $\sigma$-bond (strong interaction) is formed.

A typical example of spontaneous reaction between aromatic systems and metal salts is the auration process that has long been recognized to involve reaction between anhydrous gold(III) chloride and benzene [8]. The corresponding arylauric intermediate is highly unstable leading to $\mathrm{Au}(\mathrm{I})$ chloride and $\mathrm{PhCl}$, but, under particular circumstances, the auration products have been isolated as air- and moisture-stable crystalline solids [10].

A major outcome of these catalyst-arene interactions is that the carbon atoms of the benzene system become highly nucleophilic. This has been quantified in a theoretical investigation ( $a b$ initio study) focusing on the role of $\mathrm{AlCl}_{3}$ - and $\mathrm{BCl}_{3}$-benzene interactions in Friedel-Crafts reactions in the gas-phase [11]. Here, for the first time, a tight $\mathrm{Al}-\mathrm{C}$ contact $(2.35 \mathrm{~A})$ was found with consequent marked pyramidalization of $\mathrm{AlCl}_{3}\left(\mathrm{Cl}-\mathrm{Al} \cdots \mathrm{Cl} \approx 98^{\circ}\right)$ and loss of the benzene nodal plane. Such an interaction should be even more pronounced with electron-rich arenes or with late-transition metal-based catalysts in which the back-donation of charge should strengthen the interaction [12].

\section{3}

\section{Catalytic Enantioselective FC Reactions: An Introduction}

Despite the fact that the original studies date back more than 130 years, and the large volume of research effort devoted to FC-alkylation reactions, it has taken more than a century for asymmetric catalytic versions of this process to be developed [13]. In fact, before 1999 the examples of enantioselective catalytic FC processes were sporadic [14]. The use of chiral Lewis acids (stoichiometric amount) in the alkylation of phenols with chloral 2 was first developed by an Italian team in 1985 [15]. Here, menthol-Al Lewis acid 3 promoted the hydroxyalkylation reaction with high ortho-regiocontrol and enantioselectivity up to $80 \%$ (Scheme 1.4a). The simultaneous coordination of phenol and alkylating agent to the catalyst was postulated to account for the high regio- and stereochemical outcomes.

An enantioselective intramolecular alkylation of indoles starting from $\mathrm{N}$-hydroxytryptamine and aldehydes (Pictet-Spengler condensation) was also reported, furnishing enantiomerically enriched tetrahydro- $\beta$-carbolines (ee up to $91 \%$ ) with a stoichiometric amount of $(+)-\mathrm{Ipc}_{2} \mathrm{BCl}$ as the chiral promoter [16].

A few years later the use of chiral LAs, in catalytic amounts, for the construction of benzylic stereocenters was first reported [17]. The study considers the condensation of naphthol and ethyl pyruvate 6 with $\mathrm{ZrCl}_{3}$-dibornacyclopentadienyl 7 (5 mol\%), leading to the desired ortho-hydroxyalkylated compound 8 in moderate conversion $(70 \%)$ and good enantiomeric excess (89\%, Scheme 1.4b). However, the methodology suffered from a quite narrow scope.

Nowadays, asymmetric FC-processes have been greatly improved with the possibility of frequently isolating the products with enantioselectivities $\geq 90 \%$. This is partially due to the continued efforts in the detailed investigation of mechanistic 
1 General Aspects and Historical Background

(a)<smiles>[X]c1ccccc1</smiles>

1

(b)

5<smiles>[3H]C(Cl)(Cl)C=C[CH2+]</smiles>

2
(-)-menthol-Al(Et)Cl 3 (1 equiv)

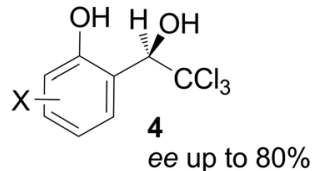<smiles>Oc1cccc2ccccc12</smiles><smiles>CCOC(=O)C(C)=O</smiles>

6

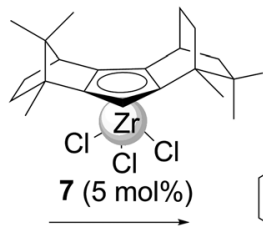

$7(5 \mathrm{~mol} \%)$<smiles>CCOC(=O)c1ccc2ccccc2c1O</smiles>
conv. $=70 \%$ ee $=89 \%$

Scheme 1.4 (a) Chiral aluminum-based complexes in the orthohydoxyalkylation of phenols; (b) first example of catalytic enantioselective FC-type alkylation arenes.

aspects, such as specific catalyst-substrate interactions, that leads to the rapid development of ever more efficient catalytic systems.

In this scenario, asymmetric organocatalysis deserves a special mention. In fact, despite its young age, it has already had an impressive impact in enantioselective aromatic functionalization, widening dramatically the scope of such methodology [14b].

In the following sections, a summary of guidelines, concerning general trends in electrophilic agents, catalysts and aromatic systems, is given in order to help the reader become oriented in the complex scenario of catalytic enantioselective aromatic functionalizations. In doing this, comprehensive literature, such as reviews and monographs, will be preferably cited, leaving more detailed descriptions of specific applications to the other contributors in this book.

\subsection{1}

\section{Alkylating Agents}

Nowadays, nearly all organic compounds with electrophilic character have been reacted with aromatics in FC-type alkylation reactions under suitable activation conditions. Starting from the most inert alkanes and cycloalkanes, that are split into reactive olefins and smaller paraffins via rearrangements, up to highly reactive carbonyl-containing compounds, a very high number of alkylating agents have been employed, among them: alkyl halides, alkenes, alkynes, epoxides, alcohols and ethers.

However, the typology of the reagents becomes slightly narrower if we limit the survey to approaches that employ chiral promoting agents in catalytic amounts able to traduce stereochemistry in the final products. Here, for instance, conventional alkylating agents for aromatic functionalization, (i.e., alkyl halides), have not found use in stereocontrolled catalytic reactions due to the intrinsic difficulties in stereodifferentiating the enantiotopic faces of the highly reactive prochiral carbocation 


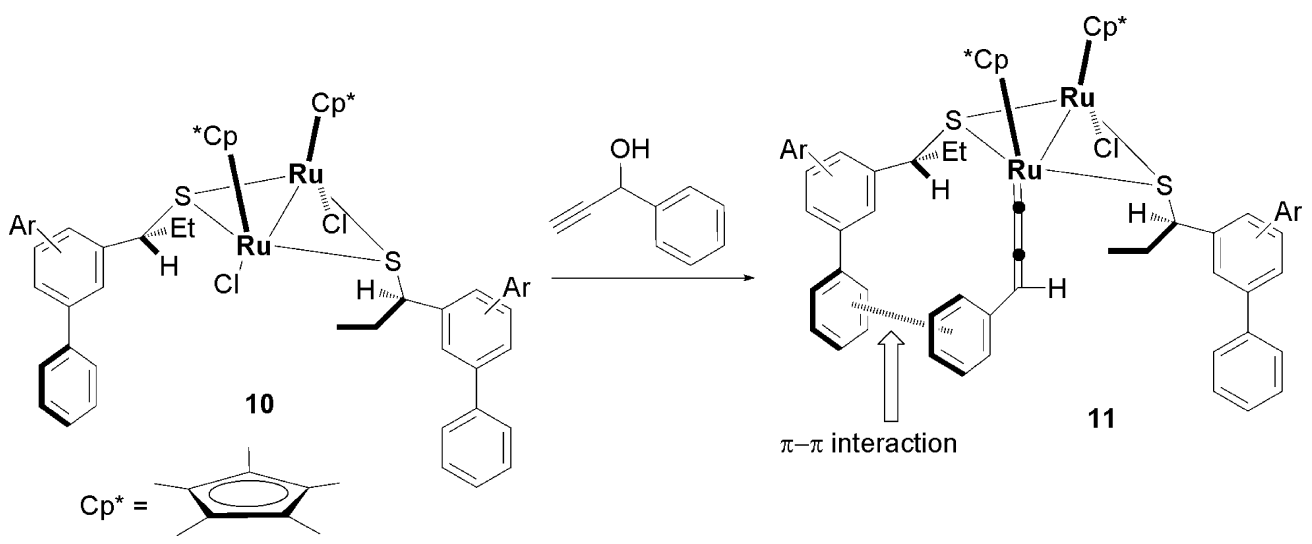

Scheme 1.5 Chiral Ru-carbenium intermediate (11) in the catalyzed enantioselective propargylic FC alkylation.

species formed during the reaction mechanism. In fact, the premature leaving of the chiral catalyst from the reactive center, with respect to the stereodiscriminating carbon-carbon forming event, precludes chiral translations in the final product.

An analogous scenario concerns the use of alcohols. They are stronger coordinating species than the analogous halides, and the direct activation of alcohols in FC-alkylations generally requires a high loading of catalyst and harsh reaction conditions. Only very recently, a specific family of chiral Ru-based complexes $\mathbf{1 0}$ has been described to be efficient in the catalytic and enantioselective alkylation of 2-methylfuran and $N, N$-dimethylaniline with propargyl alcohols through the formation of carbenium ion intermediates 11 (Scheme 1.5) [18].

Continuing the survey of $\mathrm{Csp}^{3}$-based electrophilic agents for enantioselective aromatic substitutions, oxiranes have been considered, but in this case also efficient catalytic examples are sporadic. The use of noncovalent-type activation is the only strategy investigated to date and involves the use of achiral Lewis acids with enantiomerically pure epoxides or the employment of chiral metal-based catalysts with racemic or meso substrates (Scheme 1.6). The challenging searching for a sufficiently active, but simultaneously mild catalyst, to prevent the formation of ionic intermediates, has limited the number of applications to a handful of examples with further restrictions to electron-rich heteroaromatic compounds [19]. It should be mentioned that, at present, no examples of organocatalyzed asymmetric FC-type ring-opening of epoxides have been reported.

Carbon-carbon double bonds have risen to prominence in enantioselective electrophilic aromatic substitutions due to their fine-tunable reactivity, via conjugation with electron-withdrawing groups (i.e., Michael acceptors) and via covalent and noncovalent interactions with late-transition metal complexes.

The Michael-type Friedel-Crafts alkylation is probably the most popular and investigated methodology for the direct construction of benzylic stereocenters in a stereocontrolled fashion. The activation of electron-deficient alkenes (LUMOactivation), with the simultaneous enantiodiscrimination of the arene attack, has 
(a)

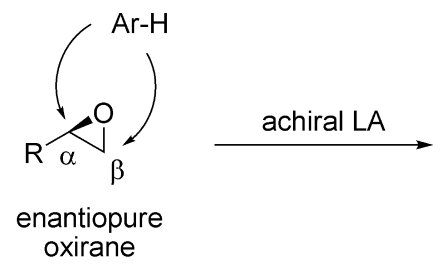

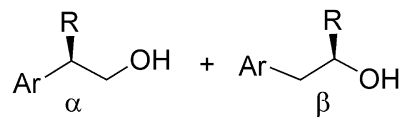

(b)
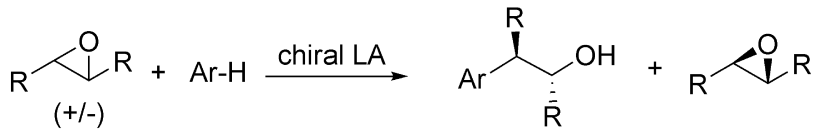

kinetic resolution

(c)

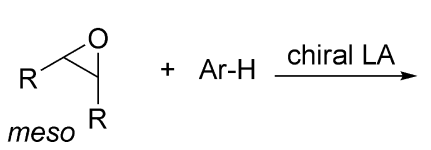

Scheme 1.6 Asymmetric electrophilic aromatic substitutions with epoxides: (a) ring-opening of enantiopure epoxides promoted by achiral catalysts; (b) kinetic resolution of racemic epoxides with chiral LAs; (c) desymmetrization of meso epoxides with chiral catalysts.

been obtained with the coordination of Lewis or Brønsted acids to the basic center of the Michael acceptor (ketones and chelating substrates) or via in situ formation of reactive iminium intermediates (mainly for $\alpha, \beta$-unsaturated aldehydes and ketones) by chiral primary or secondary amines (Scheme 1.7a). It should be mentioned, that simple $\alpha, \beta$-unsaturated acid derivatives have not yet found application in this class of reaction. The relatively poor Michael acceptor character of these compounds accounts for their inertness. On the contrary, activated chelating $\alpha, \beta$-unsaturated carboxylic acid and nitro alkene derivatives have been largely employed in stereoselective FC condensations, combined with cationic chiral Lewis acids.

Nucleophilic addition of arenes to unactivated alkenes and allenes (hydroarylation of $\mathrm{C}=\mathrm{C}$ ) is a well established procedure that requires coordinative-activation of the double bond by $\pi$-acid late metal complexes (i.e., $\mathrm{Au}, \mathrm{Pt}, \mathrm{Ru}$, etc.). The consequent lowering of the LUMO energy of the $\mathrm{C}=\mathrm{C}$ framework makes possible the nucleophilic attack of the aromatic system under high atom-economical conditions (Scheme 1.7b).

Despite the high synthetic and practical appeal of the latter approach, the use of unactivated alkenes generally requires harsh reaction conditions: high reaction temperatures, long reaction times, and the reaction scope is usually limited to electron-rich arenes or to properly functionalized aromatic systems carrying ortho-directing moieties such as: imines, pyridines, carboxylates, and so on. Finally, carbon-carbon double bonds bearing a leaving group in the allylic position found significant application in the catalytic enantioselective FC-type allylic alkylation (Scheme 1.7c). In this case, the initial insertion of the metal, in a low oxidation state, into the C-LG bond ( $\mathrm{LG}=$ leaving group) originates in the electrophilic $\eta^{3}$-metal allyl species that undergoes the FC process [20]. Several combinations of chiral metal catalysts (Ir, Pd) and FC partners have been documented. 
(a)

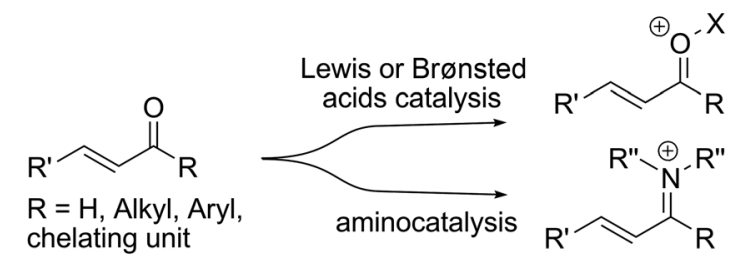

(b)

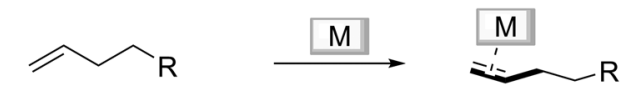

$\mathrm{M}$ : high oxidation state

(c)
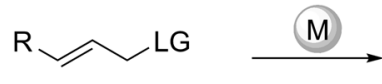

LG: leaving group

M : low oxidation state
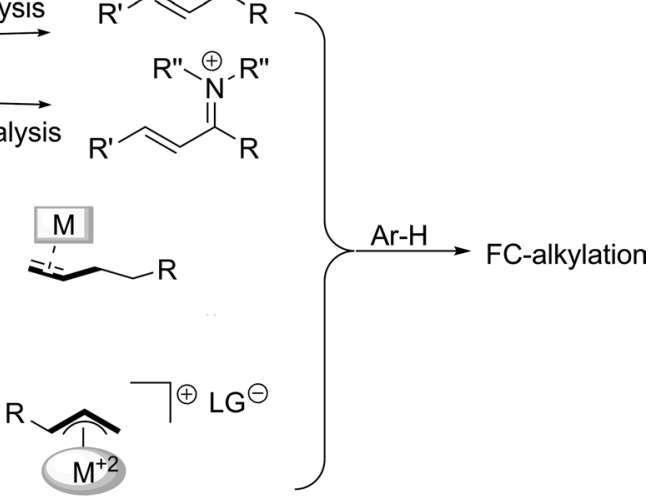

Scheme 1.7 Catalytic strategies for the use of alkenes in enantioselective functionalizations of arenes: (a) low-LUMO activation of electron-deficient carbon-carbon double bonds via covalent and noncovalent interactions; (b) unactivated olefins in FC alkylation; (c) metal-catalyzed allylic alkylation.

Finally, the 1,2-additions of arenes to carbonyl compounds have demonstrated efficiency for the construction of benzylic stereocenters in a stereocontrolled manner, in the presence of noncovalent activation with chiral Lewis and Brønsted acids. Focusing on the electrophilic partners, a high level of stereodiscrimination has been reached with activated ketones (e.g., pyruvate and trifluoropyruvates) and a marginal level with simple aldehydes and ketones. Here, in fact, the concomitant formation of bis-arylmethanes, via a dehydrative mechanism, affects markedly the use of such a type of substrate. More recently, aldo-imines, enamines and enecarbamates have also been successfully employed in the alkylation of electron-rich arenes through hydrogen-bond-type activation [21]. Contrary to the afore-described scenario of enones and enals, no covalent activation (organocatalysis), with simple carbonyl compounds, has proved efficient to date.

\subsection{2}

\section{Privileged Catalysts}

Adopting the general definition of Jacobsen and Yoon of privileged chiral catalysts [22] in Friedel-Crafts alkylations, a distinct separation between organometallic and metal-free catalysts seems convenient.

Asymmetric organometallic catalysis was first employed in the mid-1980s with a remarkable consolidation over the following two decades. A classic composition of a catalytic active metal-containing catalyst involves the presence of a catalaphor (metallic reactive site), exercising a noncovalent activation via Lewis acid catalysis, complexed with a proper chiral non-racemic organic ligand (chiraphor) that is accountable for the stereodiscrimination occurring during the process (Figure 1.2) [23]. 


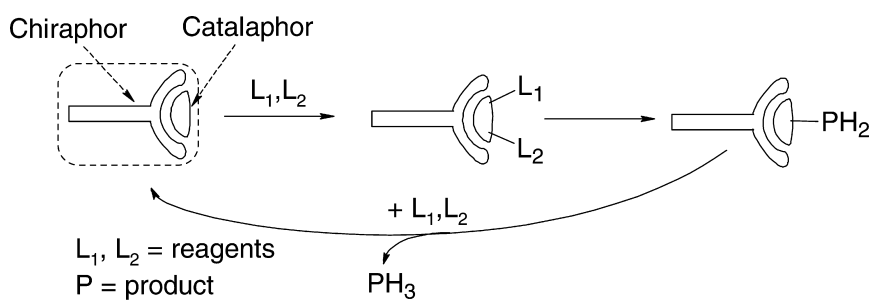

Figure 1.2 Pictorial representation of molecular composition and activity of chiral organometallic catalysts.

A collection of the most efficient organometallic catalytic systems employed in the direct construction of benzylic stereocenters is documented in Chart 1.1. Both soft and hard chiral Lewis acids have been used, ranging from transition metal (early and late) complexes to more conventional chiral systems of Group 13 elements. Among the others, cationic complexes of C2- and C3-symmetric bis-oxazolines [25] with $\mathrm{Cu}$ (II), Zn(II) and Sc(III) have found several applications in asymmetric FC chemistry involving bidentate (chelating) alkylating reagents. This prerequisite ensures the formation of rigid conformations between catalyst and electrophilic partner in the transition state with the consequent enhancement in stereodiscrimination during the aromatic species attack.

Binol-titanium and binol-zirconium adducts have also been employed in the 1,2-addition and 1,4-addition of activated aromatic compounds to simple aldehydes and enones, respectively [25]. In these cases, the real nature of the catalytically active organometallic species is unknown. Still in the area of privileged organometallic catalysts for the alkylation of aromatic compounds, Salen-metal (Al(III) and $\mathrm{Cr}$ (III)) complexes have risen to prominence for their broad scope in Michael additions and the ring-opening of epoxides.

Worthy of mention is the outstanding catalytic efficiency demonstrated also by complexes of soft late-transition metals (Pt, $\mathrm{Au}, \mathrm{Ir}, \mathrm{Pd}, \mathrm{Rh}$ ) with chiral P-ligands such as BINAP- and DPPBA-based ligands, ferrocenyl ligands, biphen and phosphoramidites. In this area, while metals in low oxidation states are generally adopted in nucleophilic allylic alkylations, cationic organometallic species featuring metal centers in a high oxidation state ( $\pi$-acceptors) have found application in stereoselective alkylations of aromatic compounds with unactivated carbon-carbon multiple bonds.

In the scenario of asymmetric organocatalysis, the iminium catalysis [26] was firstly adopted in Friedel-Crafts chemistry in 2001 by MacMillan and coworkers. Here, the outstanding performances of chiral imidazolidinones of first generation were applied in the condensation of pyrroles with enales [27]. This catalytic approach generally requires the use of a strong Brønsted acid as co-catalyst (e.g., TFA, AcOH, $\mathrm{HCl}, \mathrm{TfOH}, \mathrm{MsOH}, \mathrm{HClO}_{4}$ ) in order to improve the turn-over frequency of the reaction cycle. The pioneering study was subsequently extended by the same team and other groups, creating a large library of imidazolidinone systems with different stereochemistries for FC alkylation of more challenging substrates. Aziridine alcohols were also employed in the alkylation of indoles with $\alpha, \beta$-unsaturated aldehydes, obtaining enantiomeric excesses up to $75 \%$. Very recently, the historical 
Box-M<smiles></smiles>

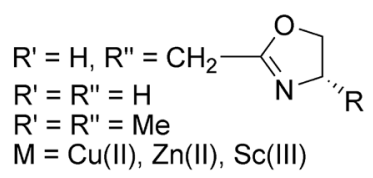

Binol-M<smiles>[X]c1cc2ccccc2c(-c2c(OC)c([X])cc3ccccc23)c1OC</smiles>

$\mathrm{X}: \mathrm{H}, \mathrm{Br}$ $[\mathrm{M}]=\mathrm{Ti}(\mathrm{OR})_{2}, \mathrm{Zr}(\mathrm{OR})_{2}$
Salen-M

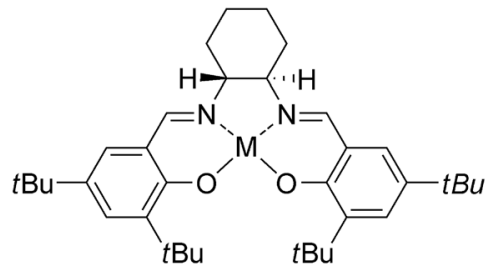

$\mathrm{M}=\mathrm{AlCl}, \mathrm{Cr}(\mathrm{Cl}) \mathrm{SbF}_{6}$
Binap-M

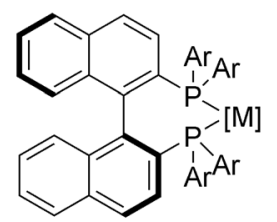

$\mathrm{Ar}=\mathrm{Ph}, p$-tolyl, 3,5-xylyl $[\mathrm{M}]=\mathrm{Pd}(\mathrm{II}), \mathrm{Cu}(\mathrm{I})$

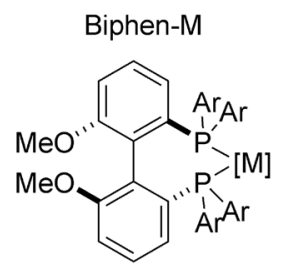

$\mathrm{Ar}=\mathrm{Ph}, 3,5-\mathrm{xy}|\mathrm{l}|-4-\mathrm{OMe}$ $[\mathrm{M}]=\mathrm{Pt}(\mathrm{II}), \mathrm{Au}(\mathrm{I})$

\section{Ferrocenyl-M}

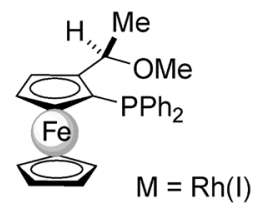

Phosphoramidite-M

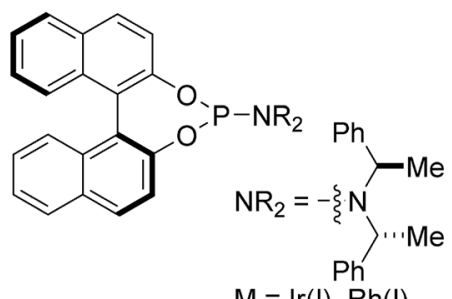

$M=\operatorname{Ir}(\mathrm{I}), \operatorname{Rh}(\mathrm{I})$

\section{DPPBA-M}

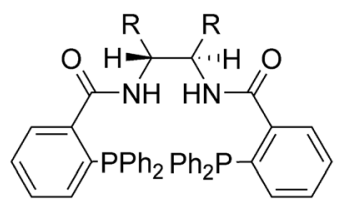

$\mathrm{R}=-\left(\mathrm{CH}_{2}\right)_{4^{-}}, \mathrm{Ph}$, naphth $[\mathrm{M}]=\mathrm{Pd}(\mathrm{II}), \operatorname{Pd}(\mathrm{O})$<smiles>Cc1cc(CN2CC[C@H]3CCC32)c(O)c(CN2CCC[C@H](C(O)(c3ccccc3)c3ccccc3)C2(O)c2ccccc2)c1</smiles>

Chart 1.1 Collection of chiral organometallic catalysts utilized in enantioselective aromatic substitutions.

tabu on the use of $\alpha, \beta$-unsaturated ketones in organocatalyzed Michael-type FC alkylation was finally solved by using chiral primary amines, such as derivatives of the natural Cinchona alkaloids [28a, b]. The hypothesis of why these amines work lies in the favorable sterical hindrance encountered in the condensation of enones and primary amines. Also in this case the role of the acidic co-catalyst was described in almost concomitant papers, with $N$-Bocphenylglycine [28c] leading to high reaction rates and enantiocontrol.

Hydrogen-bond asymmetric catalysis is the second major effort of organocatalysis in FC processes. Single-site interactions (e.g., Cinchona alkaloids, chiral phosphoric acids) and two-site binding catalysts (e.g., chiral ureas and thioureas) expanded dramatically the potential of asymmetric catalysis for the construction of complex molecular targets bearing stereochemically defined benzylic stereocenters, even through intramolecular approaches [29]. In Chart 1.2, some of the most efficient chiral architectures for organocatalytic FC processes are shown. 


\section{Iminium catalysis}<smiles>[R]C1NC([R2])([R2])N([R])C1=O</smiles><smiles>OC(c1ccccc1)(c1ccccc1)C1CN1</smiles><smiles>[X]CC1C2CN(CC2C=C)C1C(N)c1ccnc2ccccc12</smiles>

Hydrogen-bond catalysis

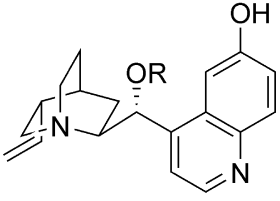

$\mathrm{R}=\mathrm{H}$, 9-phenanthryl<smiles>O[C@@H]1Cc2ccccc2[C@H]1NC(=S)Nc1cc(C(F)(F)F)cc(C(F)(F)F)c1</smiles>

$\mathrm{OH}$

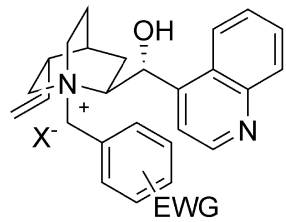

EWG<smiles>[X]P(=O)(Oc1ccccc1)Oc1c(Br)cc2ccccc2c1-c1cc2ccccc2cc1Br</smiles>

$\mathrm{Ar}=2,4,6-(\mathrm{Pr})_{3}-\mathrm{C}_{6} \mathrm{H}_{2}$ $\mathrm{X}=\mathrm{OH}, \mathrm{NHTf}$

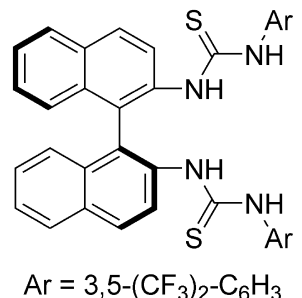

OMe<smiles>[NH]C(c1ccccc1)C([Al])N[In]</smiles>

Chart 1.2 Chiral organocatalysts for asymmetric FC alkylations, via covalent (iminium) and noncovalent activation (H-bond).

Very recently, phase transfer conditions, with chiral ammonium salts of Cinchona alkaloids, displayed their potential in the enantioselective $N(1)$-alkylation of indoles via intramolecular aza-Michael addition [30].

The growing demand for mild and green synthetic methodologies has prompted chemists to develop innovative strategies enabling the minimization of leaching of catalyst into the reaction products. Among them, immobilization of homogeneous chiral catalysts onto inert matrixes, through covalent and noncovalent attachments (heterogeneization), is among the most promising options for the recovery and reuse 


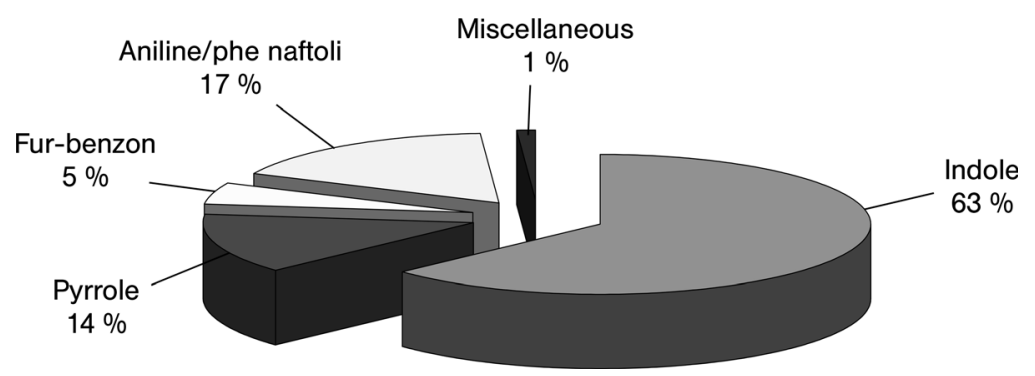

Chart 1.3 Distribution of aromatic compounds subjected to catalytic stereoselective FC-type alkylations.

of active species. Surprisingly, such an approach has been addressed and exploited only marginally in the Friedel-Crafts scenario, with scattered but effective examples in organometallic and organo-catalysis [31].

\subsection{3}

\section{Aromatic Compounds and Reaction Conditions}

Despite the remarkable developments recorded in this relatively young discipline, the most stringent limitations in applicability concern the nature of aromatic compounds. Here, the chemistry of reactive C-5-membered heteroaromatic compounds (mainly, nitrogen atom-containing indole and pyrrole derivatives) has been extensively expanded and accounts for almost $80 \%$ of the published methodologies (Chart 1.3). The presence of electron-donating as well as electron-withdrawing substituents on the heteroaromatic skeletons is generally well tolerated in these reactions, with the latter ones generally requiring higher loading of catalyst and prolonged reaction times. The use of indolyl and pyrrolyl derivatives usually enables one to control also the regiochemistry of the aromatic substitution, an important task for benzene-like analogs. In fact, while the use of indoles generally leads to selective C(3)-alkylated compounds, pyrrolyl cores direct the functionalization at the carbon atoms(s) adjacent to the nitrogen atom (C(2)-position). However, examples of different regiochemistries have been recorded, mainly for intramolecular processes or via introduction of specific sterically demanding groups on the nitrogen atom.

On the contrary, simple benzene-like compounds have received less attention due to their intrinsic inertness to reaction under the conventional catalytic reaction conditions used in asymmetric FC chemistry. In fact, the need for low reaction temperatures $\left(\leq-20^{\circ} \mathrm{C}\right)$ and the impracticability of using large excesses of aromatic compounds (intramolecular variants) led to unacceptable kinetics for synthetic purposes.

At present, an exception to this trend is constituted by a few examples of enantioselective FC alkylations exploiting unactivated alkenes in combination with late transition metal complexes. In these cases harsh reaction conditions (refluxing 
highly boiling solvents, prolonged reaction times) are needed [32]. Benzene-likearenes have found application also in examples of asymmetric organo-catalyzed transformations, with several restrictions to electron-rich systems such as amino- or alkoxy-substituted benzenes.

\section{Acknowledgments}

Financial support was provided by MIUR, Rome, and Alma Mater Studiorum, University of Bologna.

\section{Abbreviations}

DPPBA diphenylphosphino benzoic acid

EDG electro-donating groups

EWG electron-withdrawing group

LA Lewis acid

\section{References}

1 (a) Friedel, C. and Crafts, J.-M. (1877) Comptes Rendus de l'Academie des Sciences Paris, 84, 1450-1454; (b) Friedel, C. and Crafts, J.-M. (1877) Comptes Rendus de l'Academie des Sciences Paris, 84, 1392-1395; (c) Friedel, C. and Crafts, J.-M. (1877) Comptes Rendus de l'Academie des Sciences Paris, 85, 74-77.

2 Taylor, R. (1990) Electrophilic Aromatic Substitution, Wiley, Chichester.

3 (a) For extensive biographical sketches of Friedel and Crafts see Olah, G.A. and Dear, R.E.A. (1963) Historical Friedel-Crafts and Related Reactions, Wiley, New York, pp. 1-24, Chapter I; (b) Bataille, X. and Bram, G. (1998) Comptes Rendus de l'Academie des Sciences Paris, Série II, 293-296.

4 (a) Russell, G.A. (1959) Journal of the American Chemical Society, 81, 4834-4838; (b) Olah, G.A., Tashiro, M. and Kobayashi, M. (1970) Journal of the American Chemical Society, 92, 6369-6371; (c) Olah, G.A., Olah, J.A. and Ohyama, T. (1984) Journal of the American Chemical Society, 106, 5284-5290.
5 For a comprehensive treatise see: Olah, G.A. and Meyer, M.W. (1963) Intermediate Complexes, Friedel-Crafts and Related Reactions, Wiley, New York, p. 623, Chapter VIII.

6 (a) Brown, H.C., Pearsall, H. and Eddy, L.P. (1950) Journal of the American Chemical Society, 72, 5347-5347; (b) Wertyporoch, E. and Firla, T. (1933) Annali di Chimica, 500, 287; (c) Olah, G.A., Kuhn, S.J. and Olah, J.A. (1957) Journal of the Chemical Society, 2174.

7 Olah, G.A. (1994) Nobel Lecture (http://nobelprize.org/nobel_prizes/ chemistry/laureates/1994/).

8 (a) Pioneering and representative examples: Kharasch, M.S. and Isbell, H.S. (1931) Journal of the American Chemical Society, 53, 3053-3059; (b) Brown, H.C. and Wikkala, R.A. (1966) Journal of the American Chemical Society, 88, 1447-1452; (c) Olah, G.A., Hashimoto, I. and Lin, H.C. (1977) Proceedings of the National Academy of Sciences of the United States of America, 74, 4121-4125. 
9 For comprehensive treatise on the formation of $\sigma$-metal-arene bonds during the FC functionalisation of benzenes: Dyker, G.(ed.) (2005) Handbook of C-H Transformations Applications in Organic Synthesis, Wiley-VCH, Weinheim.

10 (a) de Graaf, P.W.J., Boersma, J. and van der Kerk, G.J.M. (1976) Journal of Organometallic Chemistry, 105, 399-406;

(b) Fuchita, Y., Utsunomiya, Y. and Yasutake, M. (2001) Journal of The Chemical Society - Dalton Transactions, 2330-2334;

(c) Liddle, K.S. and Parkin, C. (1972) Journal of the Chemical Society - Chemical Communications, 26-27; (d) Porter, K.A., Schier, A. and Schmidbaur, H. (2003) Organometallics, 22, 4922-4927.

11 Tarakeshwar, P., Lee, J.Y. and Kim, K.S. (1998) Journal of Physical Chemistry A, 102, 2253-2255.

12 Ottoni, O., Neder, A. de V.F., Dias, A.K.B., Cruz, R.P.A. and Aquino, L.B. (2001) Organic Letters, 3, 1005-1007.

13 (a) Jørgensen, K.A. (2003) Synthesis, 1117-1125; (b) Bandini, M. Melloni, A. and Umani-Ronchi, A. (2004) Angewandte Chemie, 116, 560-566; (2004) Angewandte Chemie - International Edition, 43, 550-556.

14 For a recent review on catalytic enantioselective aromatic functionalization see:

(a) Poulsen, T.B. and Jørgensen, K.A. (2008) Chemical Reviews, 108, 2903-2915; (b) Sheng, Y.-F., Zhang, A.-J., Zheng, X.-J. and You, S.-L. (2008) Chinese Journal of Chemistry, 28, 605-616.

15 Bigi, F., Casiraghi, G., Casnati, G., Sartori, G., Gasparri Fava, G. and Ferrari Belicchi, M. (1985) The Journal of Organic Chemistry, 50, 5018-5022.

16 Yamada, H., Kawate, T., Matsumizu, M., Nishida, A., Yamaguchi, K. and Nakagawa, M. (1998) The Journal of Organic Chemistry, 63, 6348-6354.

17 Erker, G. and van der Zeijden, A.A.H. (1990) Angewandte Chemie, 102, 562-565; (1990) Angewandte Chemie - International Edition, 29, 512-514.

18 Matsuzawa, H., Miyake, Y. and Nishibayashi, Y. (2007) Angewandte
Chemie - International Edition, 46, 6488-6491.

19 For representative examples see: (a) Bandini, M., Cozzi, P.G., Melchiorre, P. and UmaniRonchi, A. (2002) The Journal of Organic Chemistry, 67, 5386-5389; (b) Bandini, M., Cozzi, P.G., Melchiorre, P. and UmaniRonchi, A. (2004) Angewandte Chemie, 116, 83-86; (2004) Angewandte Chemie International Edition, 43, 84-87.

20 (a) Trost, B.M. and van Vranken, D.L. (1996) Chemical Reviews, 96, 395-422; (b) Helmchen, G. and Pfaltz, A. (2000) Accounts of Chemical Research, 33, 336-345; (c) Trost, B.M. and Crawley, M.L. (2003) Chemical Reviews, 103, 2921-2943.

21 (a) Terada, M. and Sorimachi, K. (2007) Journal of the American Chemical Society, 129, 292-293; (b) Jia, Y.-X., Zhong, J., Zhu, S.-F., Zhang, C.-M. and Zhou, Q.-L. (2007) Angewandte Chemie, 119, 5661-5663; (2007) Angewandte Chemie - International Edition, 46, 5565-5567.

22 Yoon, T.P. and Jacobsen, E.N. (2003) Science, 299, 1691-1693.

23 Mulzer, J. (1999) Comprehensive Asymmetric Catalysis, Vol. 1 (eds E.N. Jacobsen, A. Pfaltz and H. Yamamoto), Springer, Berlin, pp. 34-94, Chapter 3.

24 For recent reviews see: (a) Ghosh, A.K., Mathivanan, P. and Cappiello, J. (1998)

Tetrahedron: Asymmetry, 9, 1-45; (b) Jørgensen, K.A., Johannsen, M., Yao, S., Audrain, H. and Thorhauge, J. (1999) Accounts of Chemical Research, 32, 605-613; (c) Johnson, J.S. and Evans, D.A. (2000) Accounts of Chemical Research, 33, 325-335; (d) McManus, H.A. and Guiry, P.J. (2004) Chemical Reviews, 104, 4151-4202;

(e) Desimoni, G., Faita, G. and Jørgensen, K.A. (2006) Chemical Reviews, 106, 3561-3651.

25 (a) Chen, Y., Yekta, S. and Yudin, A.K. (2003) Chemical Reviews, 103, 3155-3211; (b) Brunel, J.M. (2005) Chemical Reviews, 105, 857-897.

26 (a) Erkkila, A., Majander, I. and Pihko, P.M. (2007) Chemical Reviews, 107, 5416-5470; (b) Melchiorre, P., Marigo, M., 
1 General Aspects and Historical Background

Carlone, A. and Bartoli, G. (2008)

Angewandte Chemie, 120, 6232-6265;

(2008) Angewandte Chemie - International Edition, 47, 6138-6171.

27 Paras, N.A. and MacMillan, D.W.C. (2001) Journal of the American Chemical Society, 123, 4370-4371.

28 (a) Bartoli, G. and Melchiorre, P. (2008) Synlett, 1759-1772; (b) Chen, Y.-C. (2008) Synlett, 1919-1930; Martin, N.J.A. and List, B. (2006) Journal of the American Chemical Society, 128, 13368-13369.

29 (a) Doyle, A.G. and Jacobsen, E.N. (2007) Chemical Reviews, 107, 5713-5734; (b) Akiyama, T. (2007) Chemical Reviews, 107, 5744-5758; (c) Adair, G., Mukherjee, S. and List, B. (2008) Aldrichimica Acta, 41, 31-39.

30 (a) Bandini, M., Eichholzer, A., Tragni, M. and Umani-Ronchi, A. (2008) Angewandte Chemie, 120, 3282-3285; (2008)

Angewandte Chemie - International Edition, 47, 3238-3241.

31 (a) Corma, A., GarcMa, H., Moussaif, A., Sabater, M.J., Zniber, R. and Redouane, A. (2002) Chemical Communications, 1058-1059; (b) Zhang, Y., Zhao, L., Lee, S.S. and Ying, Y.J. (2006) Advanced Synthesis and Catalysis, 348, 2027-2032;

(c) Yu, P., He, J. and Guo, C. (2008) Chemical Communications, 2355-2357;

(d) Chi, Y., Scroggins, S.T. and Fréchet,
J.M.J. (2008) Journal of the American Chemical Society, 130, 6322-6323.

32 For recent reviews on metal-catalyzed transformations of unactivated olefins see: $\mathrm{Au}(\mathrm{I}) /(\mathrm{III}):$ (a) Hashmi, A.S.K. and Hutchings, G.J. (2006) Angewandte Chemie, 118, 8064-8105; (2006) Angewandte Chemie - International Edition, 45, 7896-7936; (b) Hashmi, A.S.K. (2007) Chemical Reviews, 107, 3180-3211;

(c) Jiméez-Núñez, E. and Echavarren, A.M. (2007) Chemical Communications, 333-346; (d) Shen, H.C. (2008) Tetrahedron, 64, 3885-3903; (e) Skouta, R. Li, C.-J. (2008) Tetrahedron, 64, 4917-4938; (f) Widenhoefer, R.A. (2008) Chemistry A European Journal, 14, 5382-5391;

(g) Arcadi, A. (2008) Chemical Reviews, 108, 3266-3325; (h) Li, Z., Brouwer, C. and He, C. (2008) Chemical Reviews, 108, 3239-3265; Pt(II): (i) Chianese, A.R., Lee, S.J. and Gagné, M.R. (2007) Angewandte Chemie, 119, 4118-4136; (2007) Angewandte Chemie - International Edition, 46, 4042-4059; (j) Liu, C., Bender, C.F., Han, X. and Widenhoefer, R.A. (2007) Chemical Communications, 3607-3618; Au and Pt $\pi$-acids: Fürstner, A. and Davies, P.W. (2007) Angewandte Chemie, 119, 3478-3519; (2007) Angewandte Chemie International Edition, 46, 3410-3449. 